\title{
KAJIAN LITERATUR PENDIDIKAN AGAMA ISLAM DI SMA DAN PERGURUAN TINGGI \\ Fatkhul Mubin \\ fatkhulmubin90@gmail.com
}

\section{A. PENDAHULUAN}

Buku adalah jendela dunia. Kunci untuk membukanya adalah membaca. Ungkapan ini secara jelas menggambarkan manfaat membaca, yakni membuka, memperluas wawasan dan pengetahuan seseorang, agar bisa mengetahui lebih tentang dunia yang belum diketahui sebelumnya. Kegiatan tersebut dapat dilakukan oleh siapa saja, anak-anak, remaja, dewasa, maupun orang-orang yang telah berusia lanjut. Budaya membaca adalah kunci dari kemajuan sebuah bangsa. Kemampuan literasi baca dan tulis adalah syarat utama untuk membangun peradaban karena kemampuan literasi adalah kunci dari ilmu pengetahuan $^{1}$. Buku merupakan sumber berbagai informasi yang dapat membuka wawasan kita tentang berbagai hal seperti ilmu pengetahuan, ekonomi, sosial, budaya, politik, maupun aspek-aspek kehidupan lainnya. Selain itu, dengan membaca, dapat membantu mengubah masa depan, serta dapat menambah kecerdasan akal dan pikiran. Membaca adalah salah satu kunci penting perkembangan personal, sosial, ekonomi dan kehidupan kewargaan secara umum ${ }^{2}$. Membaca juga dikatakan sebagai bagian dari cara untuk sukses dalam hidup. Pembaca yang baik akan mampu mengembangkan sudut pandang, pengalaman dan pemikirannya. Membaca juga dipandang sebagai sebuah kecakapan tersendiri yang dibutuhkan di dalam dunia yang diarahkan oleh teknologi informasi seperti sekarang ini ${ }^{3}$. Tanpa disadari, manfaat membaca buku dapat memberikan banyak inspirasi bagi kehidupan. Namun sayangnya kegiatan membaca buku akhir-akhir ini telah banyak diabaikan berbagai kalangan dengan alasan kesibukan, maupun karena

\footnotetext{
${ }^{1}$ Lidia Endi Sulandari. 2016. "Urgensi Budaya Literasi untuk Membangun Peradaban Suatu Bangsa”, hal.6 2 sa.html, dikutip 19 Agustus 2016. 3Christina Clark and Kate Rumbold. (2006). "Reading for Pleasure." National Literacy Trust, November, h. 5, Saihu, S. (2019). RINTISAN PERADABAN PROFETIK UMAT MANUSIA MELALUI PERISTIWA TURUNNYA ADAM AS KE-DUNIA. Mumtaz: Jurnal Studi AlQuran dan Keislaman, 3(2), 268-279,

Saihu, S. (2019). Pendidikan Pluralisme Agama: Kajian tentang Integrasi Budaya dan Agama dalam Menyelesaikan Konflik Sosial Kontemporer. Jurnal Indo-Islamika, 9(1), 67-90,

Saihu, S. (2019). IMPLEMENTASI MANAJEMEN BALANCED SCORECARD DI PONDOK PESANTREN JAM'IYYAH ISLAMIYYAH TANGERANG SELATAN. Mumtaz: Jurnal Studi Al-Quran dan Keislaman, 3(1), 1-22.

Saihu, S. (2019). KOMUNIKASI PENDIDIK TERHADAP ANAK BERKEBUTUHAN KHUSUS DI SEKOLAH KHUSUS ASY-SYIFA LARANGAN. Andragogi: Jurnal Pendidikan Islam dan Manajemen Pendidikan Islam, 1(3), 418-440.

Saihu, S., \& Marsiti, M. (2019). PENDIDIKAN KARAKTER DALAM UPAYA MENANGKAL RADIKALISME DI SMA NEGERI 3 KOTA DEPOK, JAWA BARAT. Andragogi: Jurnal Pendidikan Islam dan Manajemen Pendidikan Islam, 1(1), 23-54.

Saihu, S. (2019). KONSEP MANUSIA DAN IMPLEMENTASINYA DALAM PERUMUSAN TUJUAN PENDIDIKAN ISLAM MENURUT MURTADHA MUTHAHHARI. Andragogi: Jurnal Pendidikan Islam dan Manajemen Pendidikan Islam, 1(2), 197-217.

Saihu, S., \& Rohman, B. (2019). PEMBENTUKAN KARAKTER MELALUI MODEL PENDIDIKAN TRANSFROMATIFE LEARNING PADA SANTRI DI PONDOK PESANTREN NURUL IKHLAS BALI. Edukasi Islami: Jurnal Pendidikan Islam, 8(02), 435-452.
}

\footnotetext{
3 Zurina Khairuddin 2013 “A Study of Student's Reading Interest in a Second Languange.” International Education Studies, Vol. 6 No. 11, h. 160.
} 
adanya media yang lebih praktis untuk mendapatkan informasi seperti televisi, radio, maupun media internet.

\section{B. Rumusan masalah}

1. Apa pengertian Pendidikan Agama Islam?

2. Apa perbedaan atara SMA dan perguruan tinggi ?

3. Apa yang menjadi menu bacaan pendidikan agama islam SMA dan perguruan tinggi?

\section{Tujuan}

1. Untuk mengetahui pengertian Pendidikan Agama Islam ?

2. Untuk mengetahui perbedaan atara SMA dan perguruan tinggi ?

3. Untuk mengetahui yang menjadi menu bacaan pendidikan agama islam di SMA dan perguruan tinggi?

\section{PEMBAHASAN}

\section{Pengertian Pendidikan Agama Islam}

Pendidikan dapat diartikan sebagai bimbingan secara sadar oleh pendidik terhadap perkembangan jasmani dan rohani peserta didik menuju terbentuknya kepribadian yang utama. Sehingga pendidkan dipandang sebagai salah satu aspek yang memiliki peranan pokok dalam membentuk generasi muda agar memiliki kepribadian yang utama.Dalam Islam pada mulanya pendidikan Islam disebut dengan kata "ta'dib". Kata "Ta'dib"mengacu pada pengertian yang lebih tinggi, dan mencakup unsur-unsur pengetahuan ('ilm) pengajaran (ta'lim) dan pengasuhan yang baik (tarbiyah). Akhirnya dalam perkembangan kata ta'dib sebagai istilah pendidikan telah hilang peredarannya, dan tidak dikenal lagi, sehingga ahli pendidik Islam bertemu dengan istilah At Tarbiyah atau Tarbiyah, sehingga sering disebut Tarbiyah. Sebenarnya kata ini berasal dari kata "Robbayurabbi-Tarbiyatan" yang artinya tumbuh dan berkembang. Maka dengan demikian populerlah istilah "Tarbiyah" diseluruh dunia Islam untuk menunjuk pendidikan Islam ${ }^{4}$.

\footnotetext{
${ }^{4}$ Zuhairini dkk, Metodologi Pendidikan Agama 1, (Solo: Ramadhani,1993), hlm. 9, Saihu, S., \& Taufik, T. (2019). PERLINDUNGAN HUKUM BAGI GURU. Al Amin: Jurnal Kajian Ilmu dan Budaya Islam, 2(2), $105-116$

Saihu, S. (2020). KONSEP PEMBAHARUAN PENDIDIKAN ISLAM MENURUT FAZLURRAHMAN. Andragogi: Jurnal Pendidikan Islam dan Manajemen Pendidikan Islam, 2(1), 82-95. Saihu, S. (2020). ETIKA MENUNTUT ILMU MENURUT KITAB TA'LIM MUTA'ALIM. Al Amin: Jurnal Kajian Ilmu dan Budaya Islam, 3(1), 99-112.

Saihu, Aziz, A., Mubin, F., \& Sarnoto, A. Z. (2020). Design of islamic education based on local wisdom (An analysis of social learning theories in forming character through ngejot tradition in bali). International Journal of Advanced Science and Technology, 29(6), 1278-1293.

Ronaldo, R., Zulfikar, A., Saihu, Ismail, \& Wekke, I. S. (2020). International relations of the asia pacific in the age of trump. Journal of Environmental Treatment Techniques, 8(1), 244-246.

Saihu, M. M., \& Aziz, A. (2020). Implementasi Metode Pendidikan Pluralisme Dalam Mata Pelajaran Pendidikan Agama Islam. Belajea; Jurnal Pendidikan Islam, 5(1), 131-150.

Saihu, M. (2019). Urgensi 'Urf dalam Tradisi Male dan Relevansinya dalam Dakwah Islam di JembranaBali. Jurnal Bimas Islam, 12(1), 173-201.
} 
1. Perbedaan SMA dan Perguruan tinggi

a. SMA (Sekolah Menengah Atas )

Sekolah Menengah Atas disingkat SMA, adalah jenjang pendidikan menengah pada pendidikan formal di Indonesia setelah lulus Sekolah Menengah Pertama (atau sederajat). Sekolah menengah atas ditempuh dalam waktu 3 tahun, mulai dari kelas 10 sampai kelas $12^{5}$.

b. Perguruan tinggi

Menurut UU No. 20 tahun 2003 pasal 19 ayat 1 :

"yang dimaksud perguruan tinggi adalah merupakan jenjang pendidikan setelah pendidikan menengah mencakup program pendidikan diploma, sarjana, magister, spesialis, dan doktor yang diselenggarakan oleh perguruan tinggi

Menu bacaan pendidikan agama islam di SMA dan perguruan tinggi

a. Al-quran

Al-Qur'an adalah mukjizat Islam yang kekal dan mukjizatnya diperkuat oleh kemajuan ilmu pengetahuan. Ia diturunkan Allah kepada Rasulullah saw untuk mengeluarkan manusia dari suasana yang gelap menuju yang teran, serta membimbing mereka ke jalan yang lurus. Rasulullah s.a.w. menyampaikan Al-Qur'an itu kepada para sahabatnya orangorang Arab asli sehingga mereka dapat memahaminya berdasarkan naluri mereka Apabila mereka mengalami ketidakjelasan dalam memahami suatu ayat, mereka menanyakan kepada Rasulullah s.a.w

b. Hadits

Ahli hadits dan ahli ushul berbeda pendapat dalam memberikan pengertian hadits. Di kalangan ulama hadits sendiri ada juga beberapa definisi yang antara satu sama lain agak berbeda.

Ada yang mendefinisikan hadits, adalah :

"Segala perkataan Nabi SAW, perbuatan, dan hal ihwalnya".

Ulama hadits menerangkan bahwa yang termasuk "hal ihwal", ialah segala pemberitaan tentang Nabi SAW, seperti yang berkaitan dengan himmah, karakteristik, sejarah kelahiran, dan kebiasaan-kebiasaanya.

Ulama ahli hadits yang lain merumuskan pengertian hadits dengan :

"Segala sesuatu yang bersumber dari Nabi, baik berupa perkataan, perbuatan, taqrir, maupun sifatnya".

Ulama hadits yang lain juga mendefiniskan hadits sebagai berikut :

"Sesuatu yang didasarkan kepada Nabi SAW. baik berupa perkataan, perbuatan, taqrir, maupun sifatnya".

Saihu, S. (2020). The Effect of Using Talking Stick Learning Model on Student Learning Outcomes in Islamic Primary School of Jamiatul Khair, Ciledug Tangerang. Tarbawi: Jurnal Keilmuan Manajemen Pendidikan, 6(01), 61-68.

Saihu, S. (2020). Pendidikan sosial yang terkandung dalam Surat At-Taubah Ayat 71-72. Edukasi Islami: Jurnal Pendidikan Islam, 9(01), 127-148.

5 "Wajar 12 Tahun Diberlakukan", KOMPAS, 11 Maret 2006 
Dari ketiga pengertian tersebut, ada kesamaan dan perbedaan para ahli hadits dalam mendefinisikan hadits. Kasamaan dalam mendefinisikan hadits ialah hadits dengan segala sesuatu yang disandarkan kepada Nabi SAW, baik perkataan maupun perbuatan. Sedangkan perbedaan mereka terletak pada penyebutan terakhir dari perumusan definisi hadits. Ada ahli hadits yang menyebut hal ihwal atau sifat Nabi sebagai komponen hadits, ada yang tidak menyebut. Kemudian ada ahli hadits yang menyebut taqrir Nabi secara eksplisit sebagai komponen dari bentuk-bentuk hadits.

Tetapi ada juga yang memasukkannya secara implisit ke dalam aqwal (perkataan nabi) atau afal ( perbuatan nabi) ${ }^{6}$.

\section{c. Fiqih}

Masalah fiqih adalah masalah yang dinamis dan unik untuk dikaji. Karena hukum fiqih selalu berkembang sesuai dengan keadaan zaman, fiqih selalu tampil memberikan jawaban atas problematika kehidupan manusia yang sangat komplek, sering terjadi perbedaan pendapat antara para ulama ahli fiqih dalam berbagai problem, hal ini disebabkan oleh cara pandang mereka yang berbeda-beda. Oleh karena itu penting rasanya bagi pelajar untuk mempelajari dan memahami perbandingan Madzhab secara benar agar mereka mempunyai pandangan yang luas tentang fiqih dan dapat mengaplikasiknnya sesuai dengan kondisi yang ada sehingga mereka dapat bersikap dengan bijaksana pada masyarakatnya tanpa terjadi kesalahpahaman yang memicu perpecahan dalam isalm, Karena islam itu sendiri adalah rahmatan lil alamin. Dalam makalah ini kami yakin masih banyak terdapat kekurangan, hal ini tak lain karena keterbatasan kami dalam mengkaji dan menelaah ilmu- ilmu yang berhubungan dengan fiqih secara muqaranah sehingga kami selaku penulis selalu mengharap saran dan kritik dari berbagai pihak, sehingga kami dapat memperbaikinya dikemudian hari ${ }^{7}$.

d. Aqidah akhlak

1. Pengertian Aqidah

Kata 'aqidah berasal dari kata bahasa arab. Secara bahasa, aqidah berarti sesuatu yang mengikat. Kata ini, sering juga disebut dengan 'aqa'id, yaitu kata plural (jama') dari'aqidah yang artinya simpulan. Kata lain yang serupa adalah i'tiqad, mempunyai arti kepercayaan. Menurut Sayyid Sabiq, seperti dikutip Nurcholis Madjid (baca: Cak Nur),

\footnotetext{
${ }^{6}$ Manzhur, Ibnu.Lisan Al-Arab,juz II, (Mesir: Dar Al-Mishriyah), hlm. 43

${ }^{7}$ As- shidqi, Hasbi. Pengatar ilmu fiqih. )Jakarta; Bulan bintang.) 1974, hal. 90, Aziz, A., \& Saihu, S. (2019). Interpretasi Humanistik Kebahasaan: Upaya Kontekstualisasi Kaidah Bahasa Arab. Arabiyatuna: Jurnal Bahasa Arab, 3(2), 299-214

Saihu, S. (2019). PENDIDIKAN KARAKTER BERBASIS KEARIFAN LOKAL (STUDI DI JEMBRANA BALI). Edukasi Islami: Jurnal Pendidikan Islam, 8(01), 69-90.

Şahin, C. RELIGIA.

Saihu, S., \& Mailana, A. (2019). Teori pendidikan behavioristik pembentukan karakter masyarakat muslim dalam tradisi Ngejot di Bali. Ta'dibuna: Jurnal Pendidikan Islam, 8(2), 163-176.

Mubin, F. KEADILAN DALAM GENDER: KAJIAN KEPEMIMPINAN WANITA DALAM ISLAM1,

Saihu, M. (2019). Merawat Pluralisme Merawat Indonesia (Potret Pendidikan Pluralisme Agama Di Jembrana-Bali). Deepublish.

Mubin, F. (2019). TAFSIR EMANSIPATORIS: PEMBUMIAN METODOLOGI TAFSIR PEMBEBASAN. Mumtaz: Jurnal Studi Al-Quran dan Keislaman, 3(1), 131-151.

Mubin, F. MODEL-MODEL PEMBELAJARAN BERBASIS MADRASAH DAN KEGIATAN LAIN YANG DIPERLUKAN DI DALAMNYA (FAKTOR PENDUKUNGNYA).
} 
tauhid atau al-'aqidah al-islamiyyah adalah suatu sistem kepercayaan Islam yang mencakup didalamnya keyakinan kepada Allah dengan jalan memahami nama-nama dan sifat-sifatNya, keyakinan terhadap malaikat, ruh, setan, iblis dan makhluk-makhluk gaib lainnya, kepercayaan terhadap Nabi-nabi, Kitab-kitab Suci serta hal-hal eskatologis lainnya, seperti Hari Kebangkitan (al-ba'ts), hari kiamat/hari akhir (yaum alqiyamah/yaum al-akhir), surga, neraka, syafa'at, jembatan gaib (al-shirath al-mustaqim), dan sebagainya ${ }^{8}$.

Aqidah adalah suatu keyakinan yang mengikat hatinya dari segala keraguan. Atau dengan kata lain Aqidah adalah suatu perkara yang harus dibenarkan dalam hati sehingga melahirkan jiwa yang tenang dan mantap serta tidak dipengaruhi keraguan dan meyakini dengan penuh keyakinan bahwa apa yang menjadi rukun Iman umat islam benar Mutlaq meyakini keberadaannya.

\section{Pengertian Akhlak}

Akhlak berasal dari bahasa Arab, al-khuluqu atau al-khuluq yang berarti watak, tabiat, keberanian atau agama. Sedangkan secara istilah Muuhammad Rabbi Muhammad Jauhari mengutip pendapat Ibnu Maskawaih bahwa Akhlak adalah suatu keadaan bagi jiwa yang mendorong ia melakukan tindakan-tindakan dari keadaan itu tanpa melalui fikiran dan pertimbangan. Keadaan ini terbagi dua: ada yang berasal dari tabiat aslinya, ada pula yang diperoleh dari kebiasaan yang berulan-ulang. Boleh jadi, pada mulanya tindakan-tindakan itu melalui fikiran dan pertimbangan, dan dilakukan terus-menerus, maka jadilah suatu bakat dan akhlak ${ }^{9}$.

\section{PENUTUP}

Kesimpulan Berdasarkan hasil pembahasan di atas, menu bacaan PAI SMA yang ada di masih tergolong rendah karena kurangnya referensi bacaan yang digunakan dalam proses belajar mengajar di kelas. Untuk materi al-Qur'an, hadits, fiqih akidah akhlak.. Dimana orientasi beragama yang ekstrinsik dengan intrinsik tidak ada perbedaan yang signifikan. Tentu saja ini sebagai bahan penelitian lebih lanjut untuk memperdalam aspekaspek lainnya yang mempengaruhi orientasi religius/keagamaan PAI di SMA dan perguruan tinggi seperti itu.

\footnotetext{
${ }^{8}$ Mahrus, modul Akidah, (Jakarta : 2012) hal: 9

${ }^{9}$ Muhammad Rabbi Muhammad Jauhari, Keistimewaan Akhlak Islami (Bandung: Pustaka Setia, 2006 ) hlm. 85
} 


\section{DAFTAR PUSTAKA}

"Wajar 12 Tahun Diberlakukan", KOMPAS, 11 Maret 2006

As- shidqi, Hasbi. Pengatar ilmu fiqih. )Jakarta; Bulan bintang.) 1974

Aziz, A., \& Saihu, S. (2019). Interpretasi Humanistik Kebahasaan: Upaya Kontekstualisasi Kaidah Bahasa Arab. Arabiyatuna: Jurnal Bahasa Arab, 3(2), 299214

Khairuddin, Zurina., (2013). "A Study of Student's Reading Interest in a Second Languange.” International Education Studies, Vol. 6, No. 11

Mahrus, modul Akidah, (Jakarta : 2012)

Manzhur, Ibnu.Lisan Al-Arab,juz II, (Mesir: Dar Al-Mishriyah),

Mubin, F. (2019). TAFSIR EMANSIPATORIS: PEMBUMIAN METODOLOGI TAFSIR PEMBEBASAN. Mumtaz: Jurnal Studi Al-Quran dan Keislaman, 3(1), 131-151.

Mubin, F. KEADILAN DALAM GENDER: KAJIAN KEPEMIMPINAN WANITA DALAM ISLAM1,

Mubin, F. MODEL-MODEL PEMBELAJARAN BERBASIS MADRASAH DAN KEGIATAN LAIN YANG DIPERLUKAN DI DALAMNYA (FAKTOR PENDUKUNGNYA).

Muhammad Rabbi Muhammad Jauhari, Keistimewaan Akhlak Islami (Bandung: Pustaka Setia, 2006)

Ronaldo, R., Zulfikar, A., Saihu, Ismail, \& Wekke, I. S. (2020). International relations of the asia pacific in the age of trump. Journal of Environmental Treatment Techniques, 8(1), 244-246.

Şahin, C. RELIGIA.

Saihu, Aziz, A., Mubin, F., \& Sarnoto, A. Z. (2020). Design of islamic education based on local wisdom (An analysis of social learning theories in forming character through ngejot tradition in bali). International Journal of Advanced Science and Technology, 29(6), 1278-1293.

Saihu, M. (2019). Urgensi 'Urf dalam Tradisi Male dan Relevansinya dalam Dakwah Islam di Jembrana-Bali. Jurnal Bimas Islam, 12(1), 173-201.

Saihu, M. (2019). Merawat Pluralisme Merawat Indonesia (Potret Pendidikan Pluralisme Agama Di Jembrana-Bali). Deepublish.

Saihu, M. M., \& Aziz, A. (2020). Implementasi Metode Pendidikan Pluralisme Dalam Mata Pelajaran Pendidikan Agama Islam. Belajea; Jurnal Pendidikan Islam, 5(1), 131-150.

Saihu, S. (2019). IMPLEMENTASI MANAJEMEN BALANCED SCORECARD DI PONDOK PESANTREN JAM'IYYAH ISLAMIYYAH TANGERANG SELATAN. Mumtaz: Jurnal Studi Al-Quran dan Keislaman, 3(1), 1-22.

Saihu, S. (2019). KOMUNIKASI PENDIDIK TERHADAP ANAK BERKEBUTUHAN KHUSUS DI SEKOLAH KHUSUS ASY-SYIFA LARANGAN. Andragogi: Jurnal Pendidikan Islam dan Manajemen Pendidikan Islam, 1(3), 418-440. 
Saihu, S. (2019). KONSEP MANUSIA DAN IMPLEMENTASINYA DALAM PERUMUSAN TUJUAN PENDIDIKAN ISLAM MENURUT MURTADHA MUTHAHHARI. Andragogi: Jurnal Pendidikan Islam dan Manajemen Pendidikan Islam, 1(2), 197-217.

Saihu, S. (2019). PENDIDIKAN KARAKTER BERBASIS KEARIFAN LOKAL (STUDI DI JEMBRANA BALI). Edukasi Islami: Jurnal Pendidikan Islam, 8(01), 69-90.

Saihu, S. (2019). Pendidikan Pluralisme Agama: Kajian tentang Integrasi Budaya dan Agama dalam Menyelesaikan Konflik Sosial Kontemporer. Jurnal IndoIslamika, 9(1), 67-90,

Saihu, S. (2019). RINTISAN PERADABAN PROFETIK UMAT MANUSIA MELALUI PERISTIWA TURUNNYA ADAM AS KE-DUNIA. Mumtaz: Jurnal Studi AlQuran dan Keislaman, 3(2), 268-279,

Saihu, S. (2020). ETIKA MENUNTUT ILMU MENURUT KITAB TA'LIM MUTA'ALIM. Al Amin: Jurnal Kajian Ilmu dan Budaya Islam, 3(1), 99-112.

Saihu, S. (2020). KONSEP PEMBAHARUAN PENDIDIKAN ISLAM MENURUT FAZLURRAHMAN. Andragogi: Jurnal Pendidikan Islam dan Manajemen Pendidikan Islam, 2(1), 82-95.

Saihu, S. (2020). Pendidikan sosial yang terkandung dalam Surat At-Taubah Ayat 7172. Edukasi Islami: Jurnal Pendidikan Islam, 9(01), 127-148.

Saihu, S. (2020). The Effect of Using Talking Stick Learning Model on Student Learning Outcomes in Islamic Primary School of Jamiatul Khair, Ciledug Tangerang. Tarbawi: Jurnal Keilmuan Manajemen Pendidikan, 6(01), 61-68.

Saihu, S., \& Mailana, A. (2019). Teori pendidikan behavioristik pembentukan karakter masyarakat muslim dalam tradisi Ngejot di Bali. Ta'dibuna: Jurnal Pendidikan Islam, 8(2), 163-176.

Saihu, S., \& Marsiti, M. (2019). PENDIDIKAN KARAKTER DALAM UPAYA MENANGKAL RADIKALISME DI SMA NEGERI 3 KOTA DEPOK, JAWA BARAT. Andragogi: Jurnal Pendidikan Islam dan Manajemen Pendidikan Islam, 1(1), 23-54.

Saihu, S., \& Rohman, B. (2019). PEMBENTUKAN KARAKTER MELALUI MODEL PENDIDIKAN TRANSFROMATIFE LEARNING PADA SANTRI DI PONDOK PESANTREN NURUL IKHLAS BALI. Edukasi Islami: Jurnal Pendidikan Islam, 8(02), 435-452.

Saihu, S., \& Taufik, T. (2019). PERLINDUNGAN HUKUM BAGI GURU. Al Amin: Jurnal Kajian Ilmu dan Budaya Islam, 2(2), 105-116.

Sulandari, Lidia Endi. (2016). "Urgensi Budaya Literasi untuk Membangun Peradaban Suatu Bangsa"

Zuhairini dkk. 1993. Metodologi Pendidikan Agama 1. Solo: Ramadhani. 
